УДК 539.621: 539.3

DOI: $10.18372 / 0370-2197.4(89) .15006$

\author{
М. В. ЧЕРНЕЦЬ ${ }^{1}$, А. О. КОРНІЕНКО ${ }^{1}$, С. В. ФЕДОРЧУК ${ }^{1}$, О. В. РАДІОНЕНКО \\ ${ }^{1}$ Національний авіаційний університет, Київ \\ ${ }^{2}$ Приазовський державний технічний університет, Маріуполь
}

\title{
РОЗРАХУНКОВА ОЦІНКА РЕСУРСУ ЦИЛІНДРИЧНИХ І ПЛОСКИХ МЕТАЛОПОЛІМЕРНИХ НАПРЯМНИХ КОВЗАННЯ ПРИ ГРАНИЧНОМУ ТЕРТІ
}

\begin{abstract}
Наведено методи розрахунку контактних тисків і ресурсу изиліндричних та плоских металополімерних напрямних ковзання, в основу яких покладено відому методологію дослідження кінетики зношування матеріалів при терті ковзання. Проведено розрахунок ресурсу обох видів напрямних з гібридним спряженням матеріалів при різних навантаженнях та радіальних зазорах (ииліндрична напрямна). Повзун напрямної виконано з антифрикційного полімерного композиційного матеріалу "Моглайс», а ї̈ основу зі сталі. Також визначено максимальні початкові контактні тиски у ииліндричній напрямній. Встановлено кількісні і якісні закономірності залежності шляху тертя та контактних тисків від навантаження і радіального зазору.
\end{abstract}

Ключові слова: циліндричні і плоскі металополімерні напрямні, метод розрахунку довговічності і навантажувальної здатності, ресурс напрямних - илях тертя, максимальні контактні тиски

Напрямні широко застосовують для утримання у контакті рухомих частин різноманітного обладнання та механізмів при їх взаємопереміщенні. Найбільш розповсюдженими в машинобудуванні є напрямні для забезпечення прямолінійного руху деталей. Циліндричні напрямні поступального або зворотно - поступального руху поряд з плоскими напрямними знаходять досить широке застосування в сучасній техніці в різноманітних машинах і обладнанні. Можна вказати на такі області застосування циліндричних та плоских напрямних: ковальсько пресове обладнання, металорізальні верстати, приводи позиціонування, підйомно - транспортні механізми, пакувальне обладнання, лабораторне та медичне обладнання, обладнання для харчової промисловості, обладнання для оброблення деревини та пластмас, прилади та вимірювальні пристрої.

Незважаючи на практичну необхідність проектного розрахунку їх довговічності або зношування на стадії проектування, для циліндричних напрямних ковзання не розроблені відповідні розрахункові методи. Нижче наведено результати розрахунку такого виду напрямних ковзання, де застосовують полімерні композити, зокрема Моглайс, з використанням модифікованого методу дослідження кінетики зношування при терті ковзання $[1,8,13]$. Відомі в літературі розрахункові методи [2-7] звичайних підшипників ковзання 3 металевими елементами практично не були використовувані з метою прогнозування довговічності або зношування зазначеного типу трибосистем ковзання 3 металевими елементами, а тим більше для металополімерних циліндричних напрямних. Лише у працях [9-13] першим автором досліджувались такі триботехнічні системи ковзання з металевими елементами. Також у [14] проведено розрахунок параметрів контакту і сил тертя в металевих циліндричних напрямних ковзання.

Постановка задачі. Циліндричні напрямні прямолінійного зворотно - поступального руху зображені на рис. 1 . 


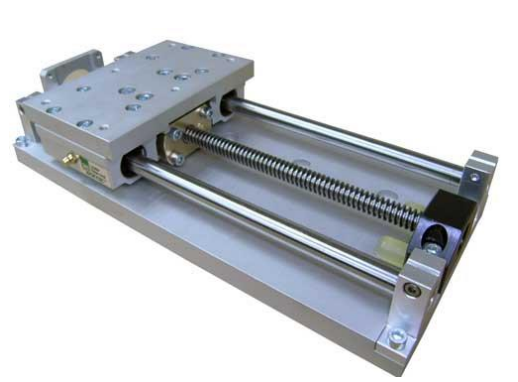

$a$

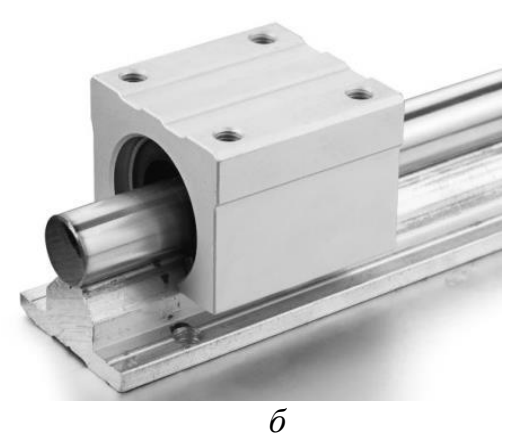

$\sigma$

Рис. 1. Циліндричні напрямні ковзання з двома та однією основами

Циліндрична напрямна моделюється пружною основою 2, по якій 3 постійною швидкістю $v$ здійснює зворотно - поступальний рух пружний повзун 33 запресованою втулкою 1 (рис. 2). У з'єднанні має місце радіальний зазор $\varepsilon=R_{1}-R_{2}$. Матеріали напрямної можуть мати різні характеристики пружності і різну зносостійкість. На повзун 3 діс робоче зусилля $F$, під впливом якого в області контакту $2 \alpha_{0}$ виникають контактні тиски $p(\alpha)$, величина і розподіл яких невідомі. Розв'язок задачі проводиться як плоскої задачі теорії пружності з навантаженням $N=F / l_{1}$, де $l_{1}$ довжина втулки.

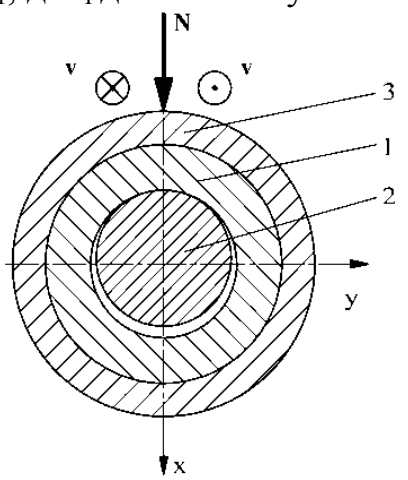

$a$

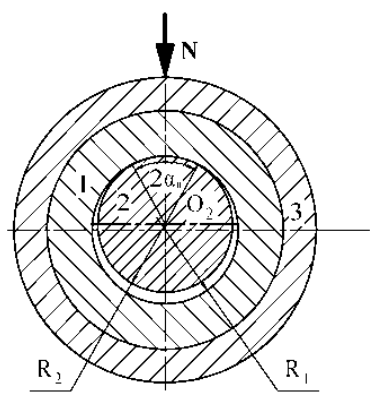

$\sigma$

Рис. 2. Схеми циліндричної напрямної ковзання: $a$ - загальна, $\sigma$ - розрахункова

Визначення початкових контактних тисків. Для обчислення початкових статичних контактних тисків $p_{\alpha}$, що виникають в області контакту елементів циліндричної напрямної, використовується наступне інтегро-диференціальне рівняння $[1,9,13]$ :

$$
c_{1} \int_{-\alpha_{0}}^{\alpha_{0}} \cot \frac{\alpha-\theta}{2} p_{\theta}^{\prime} d \theta=c_{2} p_{\alpha}+c_{3} \int_{-\alpha_{0}}^{\alpha_{0}} p_{\alpha} d \alpha+c_{4} \cos \alpha \int_{-\alpha_{0}}^{\alpha_{0}} p_{\alpha} \cos \alpha d \alpha+\frac{\varepsilon}{R^{2}},
$$

де $p_{\theta}^{\prime}=d p / d \theta ; \alpha-$ полярний кут; $0 \leq \alpha \leq \theta, \quad 0 \leq \theta \leq \alpha_{0} ;$

$c_{1}=\frac{1}{8 \pi}\left(\frac{1+\kappa_{1}}{G_{1} R_{1}}+\frac{1+\kappa_{2}}{G_{2} R_{2}}\right) ; c_{2}=\frac{1}{4}\left(\frac{1-\kappa_{1}}{G_{1} R_{1}}-\frac{1-\kappa_{2}}{G_{2} R_{2}}\right) ; c_{3}=\frac{1+\kappa_{1}}{8 \pi G_{1} R_{1}} ; c_{4}=\frac{1}{2 \pi}\left(\frac{\kappa_{1}}{G_{1} R_{1}}+\frac{1}{G_{2} R_{2}}\right) ;$

$R_{1} \approx R_{2}=R ; G_{1}, G_{2}$ - модулі зсуву матеріалів; $v_{1}, v_{2}-$ їх коефіцієнти Пуасона; $\kappa=3-4 v-$ постійна Мусхелішвілі, $E=2 G /(1+v)-$ модуль Юнга. 
Наближений розв'язок рівняння (1) для визначення тисків $p_{\alpha}$ проводиться методом колокації для однієї точки колокації $\alpha=0.5 \alpha_{0}$. Функція контактного тиску має вигляд [1, 13]

$$
p_{\alpha} \approx E_{0} \varepsilon \sqrt{\tan ^{2} \frac{\alpha_{0}}{2}-\tan ^{2} \frac{\alpha}{2}},
$$

де $E_{0}=\left(e_{4} / R_{2}\right) \cos ^{2}\left(\alpha_{0} / 4\right)-$ коефіцієнт колокації, $e_{4}=16 G_{1} G_{2}\left(1+v_{1}\right)\left(1+v_{2}\right) / Z$, $Z=2 G_{2}\left(1+\kappa_{1}\right)\left(1+v_{1}\right)\left(1+v_{2}\right)+2 G_{1}\left(1+\kappa_{2}\right)\left(1+v_{2}\right)\left(1+v_{1}\right)$.

Для визначення невідомого півкута контакту $\alpha_{0}$ використовується умова рівноваги сил, прикладених до циліндричної основи

$$
N=R_{2} \int_{-\alpha_{0}}^{\alpha_{0}} p_{\alpha} \cos \alpha d \alpha=4 \pi R_{2} E_{0} \varepsilon \sin ^{2}\left(\alpha_{0} / 4\right) .
$$

Трибокінетична модель дослідження зношування. Для вирішення даної зносоконтактної задачі використовується раніше розроблена відома математична модель зношування матеріалів при терті ковзання [1, 8-13].

Зносоконтактні тиски, які діють у підшипнику у процесі зношування елементів, визначаються так:

$$
p_{\alpha h}=p_{\alpha}+p_{h},
$$

де $p_{h}-$ зміна початкових тисків внаслідок зношування.

Для їх опису використовується залежність

$$
p_{h}=E_{h} \varepsilon_{h} \sqrt{\tan ^{2} \frac{\alpha_{0 h}}{2}-\tan ^{2} \frac{\alpha}{2}},
$$

де $E_{h}=c_{h}\left(e_{4} / R_{2}\right) \cos ^{2}\left(\alpha_{0 h} / 4\right), c_{h}>0$ - показник темпу зношування.

Для визначення півкута трибоконтакту $\alpha_{0 h}$, що характеризує зону контакту при зношуванні, використовується умова, подібна до умови (3)

$$
N=4 \pi R_{2} E_{0}\left(\varepsilon+c_{\alpha h^{2}} \varepsilon_{h}\right) \sin ^{2}\left(\alpha_{0 h} / 4\right),
$$

де $\varepsilon_{h}=h_{k \max }\left(-K_{t}^{(k)}+h_{k}^{\prime}\right) ; h_{1}^{\prime}=h_{2} / h_{1}, h_{2}^{\prime}=h_{1} / h_{2}-$ відносні зношування у трибосистемі; $K_{t}^{(1)}, K_{t}^{(2)}$ - коефіцієнти взаємного перекриття елементів напрямної при рухомому контакті; $c_{\alpha h}$ - показник темпу приросту кута трибоконтакту;

$$
\begin{aligned}
& h_{1}^{\prime}=\frac{h_{2}}{h_{1}}=\frac{\Phi_{1}(\tau)}{\Phi_{2}(\tau)}=\frac{B_{1} \tau_{01}^{m_{1}}\left(\tau-\tau_{02}\right)^{m_{2}}}{B_{2} \tau_{02}^{m_{2}}\left(\tau-\tau_{01}\right)^{m_{1}}} K_{t}^{(2)}, \\
& h_{2}^{\prime}=\frac{h_{1}}{h_{2}}=\frac{\Phi_{2}(\tau)}{\Phi_{1}(\tau)}=\frac{B_{2} \tau_{02}^{m_{2}}\left(\tau-\tau_{01}\right)^{m_{1}}}{B_{1} \tau_{01}^{m_{1}}\left(\tau-\tau_{02}\right)^{m_{2}}} K_{t}^{(1)} ; \quad \tau=f p_{0} .
\end{aligned}
$$

Максимальні контактні тиски $p_{0}$ виникають при $\alpha=0$. Тоді

$$
p_{0} \approx E_{0} \varepsilon \tan \left(\alpha_{0} / 2\right) \text {. }
$$

Згідно $[1,13]$ розрахункове співвідношення для прогнозної оцінки довговічності $t$ напрямної при заданому зношуванні $h_{1}=h_{k \max }$ втулки має вигляд

$$
t=\frac{-B_{k} \tau_{0 k}^{m_{k}}}{v c_{h} \tau_{h} \Sigma_{k}\left(1-m_{k}\right) K_{t}^{(k)}}\left\{\left[\tau-\tau_{0 k}\right]^{1-m_{k}}-\left[\left(\tau-\tau_{k 0}\right)+c_{h} h_{k \max } \Sigma_{k} \tau_{h}\right]^{1-m_{k}}\right\},
$$


де $\Sigma_{1}=\left(-K_{t}^{(1)}+h_{1}^{\prime}\right), \Sigma_{2}=\left(K_{t}^{(2)}-h_{2}^{\prime}\right) ; K_{t}^{(1)}=1, K_{t}^{(2)}=\alpha_{0} / \pi$.

Відповідно питома сила тертя при зношуванні

$$
\tau_{h}=f p_{0 h}=f E_{h} \tan \left(\alpha_{0 h} / 2\right) .
$$

Після відповідних перетворень виразу (9) отримано формулу для обчислення лінійного зношування повзуна 1 і основи 2 напрямної при заданому ресурсі $t_{*}$ iï роботи у вигляді

$$
h_{k}=\left|\frac{1}{c_{h} \tau_{h} K_{t}^{(k)} \Sigma_{k}}\left[H_{k}-\sqrt[1-m_{k}]{\frac{L_{k} H_{k}^{1-m_{k}}-t_{*}}{L_{k}}}\right]\right|
$$

де $L_{k}=B_{k} \tau_{0 k}^{m_{k}} / c_{h} v \tau_{h}\left(1-m_{k}\right) \Sigma_{k} K_{t}^{(k)}, H_{k}=\tau-\tau_{0 k}$.

Лінійні зношування $h_{k}$ елементів напрямної є взаємопов'язаними

$$
h_{1}=h_{2} h_{2}^{\prime} / K_{t}^{(2)}, h_{2}=h_{1} h_{1}^{\prime} / K_{t}^{(1)} .
$$

Для цього виду трибомеханічної системи ковзання однак доцільніше визначати граничний шлях тертя ковзання $L_{*}$

$$
L_{*}=\frac{-B_{k} \tau_{0 k}^{m_{k}}}{c_{h} \tau_{h}\left(1+h_{k}^{\prime}\right)\left(1-m_{k}\right) K_{t}^{(k)}}\left\{\left(\tau-\tau_{0 k}\right)^{1-m_{1}}-\left[\left(\tau-\tau_{0 k}\right)+c_{h} h_{k \max } \Sigma_{k} \tau_{h}\right]^{1-m_{k}}\right\},
$$

Широко також застосовують і плоскі прямолінійні напрямні різного виду, зокрема на рейковій основі (рис. 3).

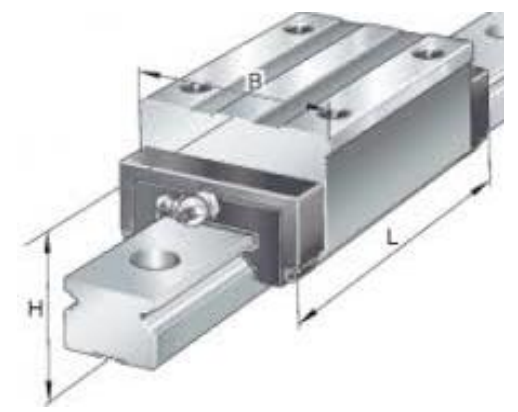

Рис. 3. Плоска напрямна прямолінійного руху

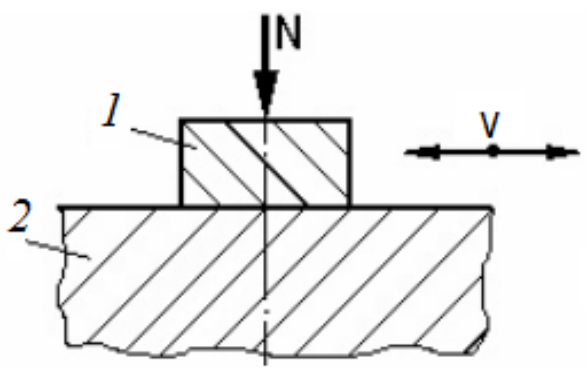

Рис. 4. Розрахункова схема плоскої напрямної: повзун (каретка) 1, основа 2

Оскільки контактні тиски у такій трибосистемі ковзання залишаються незмінними при зношуванні їі елементів, тому і питома сила тертя $\tau=f p=$ const, $\mathrm{i}$, відповідно, розрахункові залежності для шляху тертя та лінійного зношування будуть значно простішими. У напрямних повзун 1 зношується постійно, а основа 2 у $K_{t}$ разів менше. Коефіцієнти взаємного перекриття $K_{t}^{(2)}$ основи і $K_{t}^{(1)}$ повзуна

$$
K_{t}^{(2)}=A_{1} / A_{2}, \quad K_{t}^{(1)}=1,
$$

де, відповідно, $A_{1}, A_{2}$ - площі тертя повзуна і основи.

Тоді вирази для шляху тертя та лінійного зношування з урахуванням того, що розраховуються триботехнічні параметри повзуна 1, матимуть вигляд [15] 


$$
L_{1}=\frac{B_{1}}{K_{t}^{(1)}}\left(\frac{\tau_{01}}{\tau-\tau_{01}}\right)^{m_{1}} h_{1}, \quad h_{1}=\frac{L_{1} K_{t}^{(1)}}{B_{1}}\left(\frac{\tau-\tau_{01}}{\tau_{01}}\right)^{m_{1}}
$$

де $\tau=f p=$ const,

$$
p=N / A_{1}=\text { const } .
$$

Зношування $h_{2}$ основи через досягнуте зношування $h_{1}$ повзуна обчислюється за виразом

$$
h_{2}=h_{1} h_{1}^{\prime}
$$

Числовий розв'язок задачі.

Дані для розрахунку циліндричної напрямної (рис. 1, б): $F=500,1000,2000$ $\mathrm{H} ; N=F / l_{1}=5,10,20 \mathrm{H} / \mathrm{мм}, l_{1}=100$ мм - довжина втулки повзуна, $l_{2}=500$ мм довжина основи; $K_{t}^{(2)}=0.2, K_{t}^{(1)}=1 ; \varepsilon=0.05,0.075,0.1$ мм (посадка з зазором $\mathrm{H} 9 / \mathrm{d} 9) ; D_{2}=40$ мм; $f=0.09-$ граничне тертя; $h_{1 *}=0.5$ мм - допустиме зношування втулки.

Матеріали елементів трибосистеми:

- втулка повзуна: полімерний композит Моглайс [16]: $E_{M}=11.2$ ГПа, $v_{\mathrm{M}}=$ $0.4 ; B_{1}=1,12 \cdot 10^{9} ; m_{1}=1.9, \tau_{01}=0,05 \mathrm{MПа}-$ його характеристики зносостійкості.

- основа: сталь 45: $E_{2}=210$ ГПа, $v_{2}=0.3 ; B_{2}=2,2 \cdot 10^{10}, m_{2}=2.1, \tau_{02}=0.1 \mathrm{MПа.}$

Дані для розрахунку плоскої напрямної (рис. 3): $F=500,1000,2000 \mathrm{H}$; $p=1.25,2.5,5 \mathrm{MПа,} A_{1}=400 \mathrm{mм}^{2}$ - площа контакту повзуна 13 основою 2; $l_{1}=100 \mathrm{MM}, l_{2}=500 \mathrm{Mм}$.

Проведено розрахунок шляху тертя обох видів напрямних при однаковому навантаженні на повзун. Результати розрахунку наведено на рис. 5, 6

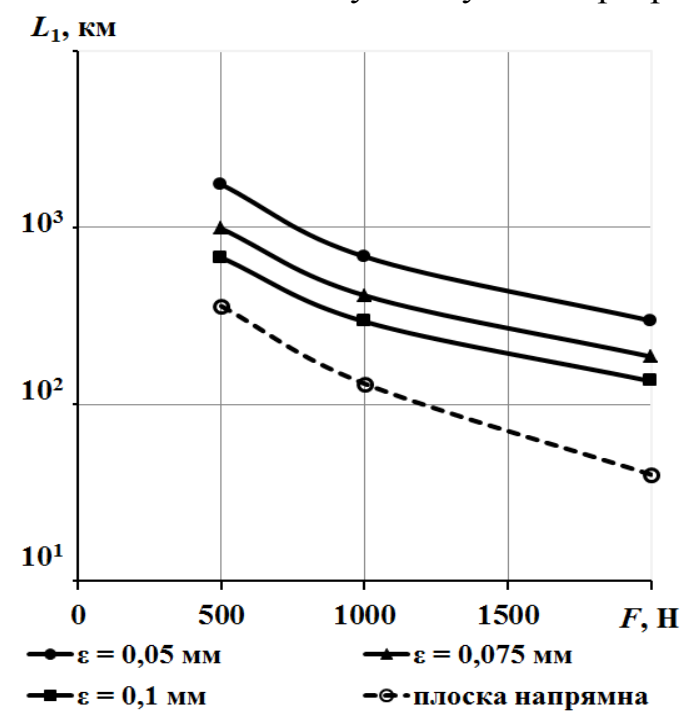

Рис. 5. Ресурс напрямних

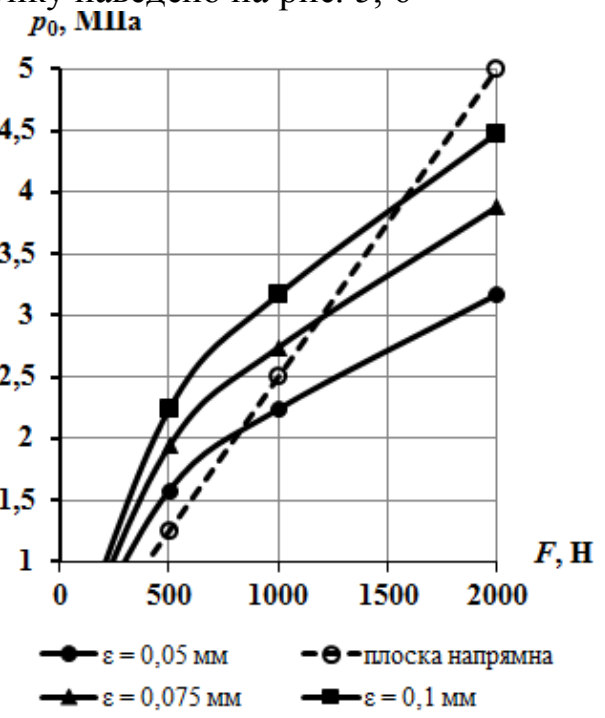

Рис. 6. Максимальні контактні тиски у напрямних

Зокрема на рис. 5 наведено залежність шляху тертя повзуна від навантаження і радіального зазору (циліндрична напрямна). Шлях тертя у циліндричній напрямній залежить від радіального зазору. Його зниження $\epsilon$ різним із зростанням навантаження (табл. 1). 
Таблиия 1

\begin{tabular}{|c|c|c|c|}
\hline \multirow{2}{*}{$\varepsilon$, мм } & \multicolumn{3}{|c|}{$F, \mathrm{H}$} \\
\cline { 2 - 4 } & 500 & 1000 & 2000 \\
\hline 0,05 & 1756 & 685 & 297 \\
\hline 0,075 & $987(1,78$ p. $)$ & $413(1,66$ p. $)$ & $186(1,6$ p. $)$ \\
\hline 0,1 & $677(2,59$ p. $)$ & $294(2,33$ p. $)$ & $135(2,2$ p. $)$ \\
\hline
\end{tabular}

Примітка: $t_{\varepsilon=0,05} / t_{\varepsilon=0,1}=1756 / 677=2,59$ рази;

$t_{N=500} / t_{N=2000}=1756 / 297=5,91$ рази $(\varepsilon=0,05 \mathrm{мм}) ;$

$t_{N=500} / t_{N=2000}=1756 / 187=5,31$ рази $(\varepsilon=0,075 \mathrm{мм}) ;$

$t_{N=500} / t_{N=2000}=677 / 135=5,01$ рази $(\varepsilon=0,1 \mathrm{мм})$.

Шлях тертя у плоскій напрямній до досягнення допустимого зношування повзуна $h_{1 *}=0,5$ мм із зростанням у чотири рази навантаження $F$ знижується у $360 / 40=9$ разів.

Ресурс плоскої напрямної є меншим, ніж циліндричної напрямної. Їх відношення залежить від $\varepsilon$ і $F$ (табл. 2).

Таблиия 2

\begin{tabular}{|c|c|c|c|}
\hline \multirow{2}{*}{$\varepsilon$, мм } & \multicolumn{3}{|c|}{$F$, Н } \\
\cline { 2 - 4 } & 500 & 1000 & 2000 \\
\hline 0,05 & $1756 / 360=4,88$ рази & $685 / 131=5,23$ рази & $297 / 40=7,245$ рази \\
\hline 0,075 & $987 / 360=2,74$ рази & $413 / 131=3,15$ рази & $186 / 40=4,65$ рази \\
\hline 0,1 & $677 / 360=1,88$ рази & $294 / 131=2,24$ рази & $135 / 40=3,375$ рази \\
\hline
\end{tabular}

На рис. 6 подано максимальні контактні тиски у залежності від навантаження на повзун та радіального зазору у циліндричній напрямній. Зростання початкового контактного тиску $p_{0} \epsilon$ нелінійним при зростанні навантаження $F$. Тобто якщо у циліндричній напрямній $F$ зростає у 4 рази, то $p_{0}$ зростає у $\sqrt{4}=2$ рази при усіх величинах радіального зазору $\varepsilon$. Із зменшенням $\varepsilon$ у 2 рази тиск знижується у $\sqrt{2}=1,414$ рази.

У плоскій напрямній тиск $p_{0}$ зростає прямопропорційно навантаженню $F$. Тут тиски $p_{0}$ залишатимуться незмінними під час зношування композиту внаслідок незмінності площі площинного співдотику. Натомість у циліндричній напрямній зношування втулки призведе до зниження величини початкового тиску $p_{0}$, тобто до зростання iї довговічності. Це корисна властивість такого виду спряження циліндричних тіл.

\section{Список літератури}

1. Андрейкив А.Е., Чернец М.В. Оценка контактного взаимодействия трущихся деталей машин. - К.: Наукова думка, 1991. -160 с.

2. Горячева И.Г., Добычин Н.М. Контактные задачи в трибологии. - М.: Машиностроение, 1988. - 256 с.

3. Коваленко Е.В. К расчету изнашивания сопряжения вал - втулка // ММТ. - 1982. - № 6. - С.66-72.

4. Кравчук А.С., Чигарев А.В. Механика контактного взаимодействия тел с круговыми границами. - Минск: Технопринт, 2000. - 198 с.

5. Крагельский И.В., Добычин Н.М., Комбалов В.С. Основы расчетов на трение и износ. - М.: Машиностроение, 1977. -526 с.

6. Кузьменко А.Г. Развитие методов контактной трибомеханики. - Хмельницкий: XНУ, 2010. 
7. Теплый М.И. Определение контактных параметров и износа в цилиндрических опорах скольжения // Трение и износ. - 1987. -№ 6. - С. 895-902.

8. Чернец М.В. К вопросу об оценке долговечности цилиндрических трибосистем скольжения с границами, близкими к круговым // Трение и износ. - 1996. -№ 3. - С. 340-344.

9. Czerniec M. Wytrzymałość stykowo - tarciowa oraz trwałość tribotechnicznych systemów ślizgowych. - Lublin: Wyd. Politechniki Lubelskiej, 2000. - $490 \mathrm{~s}$.

10. Чернец М.В., Лебедева Н.М. К вопросу о влиянии малой некруглости элементов цилиндрической направляющей на ее долговечность // Проблеми трибології. - 2005. №3. - С. $100-106$.

11. Чернець М.В., Лєбєдєва Н.М. Дослідження впливу малої некруглості на ресурс циліндричної напрямної // Проблеми трибології. - 2006. -№4. - С. 52 - 55.

12. Чернець М.В., Андрейків О.С., Лєбєдєва Н.М. Узагальнений метод дослідження трибоконтактної взаємодії у циліндричний напрямній з різнотипним ограненням іï елементів // Машинознавство. - 2006. - №7. - С. 54 - 58.

13. Чернець М.В. Трибоконтактні задачі для циліндричних з'єднань 3 технологічною некруглістю. - Люблін: Вид. Люблінської політехніки, 2013. - 274 с.

14. Вельбой В.П., Диха М.О. До розрахунку контактних параметрів і сил тертя в циліндричних напрямних ковзання // Проблеми трибології. -2016. - № 4. - С. $82-88$.

15. Чернець М. В., Іщенко А. О., Корнієнко А. О., Радіоненко О. В., Федорчук С. В. До питання про метод розрахунку довговічності плоских напрямних ковзання з елементами 3 полімерних композитів // Проблеми тертя та зношування. - 2020. - № 3 (88). С.40-46. ДОІ: 10.18372/0370-2197.3(88).14919.

16. Ищенко А.А., Радионенко А.В., Ищенко Е.А. Исследование и применение полимерного материала «моглайс» для восстановления направляющих поверхностей салазок суппортов металлорежущих станков // Проблеми тертя та зношування. - 2014. - №1 (62). C. $23-29$.

Стаття надійшла до редакції 16.11.2020.

Чернець Мирон Васильович - д-р техн. наук, професор, провідний науковий співробітник Національного авіаційного університету, myron.czerniec@ gmail.com

Корніснко Анатолій Олександрович - канд. техн. наук, старший науковий співробітник, доцент кафедри машинознавства стандартизації та сертифікації Національного авіаційного університету.

Федорчук Світлана Володимирівна - старший викладач кафедри машинознавства, стандартизації та сертифікації, Національний авіаційний університет.

Радіоненко Олександр Васильович - канд. техн. наук, доцент кафедри «Технологія машинобудування» ДВНЗ «Приазовський державний технічний університет», вул. Університетська 7, м. Маріуполь, Україна, 87555, тел.: + 3806294465 89, E-mail: radav50mar@gmail.com. 
M. V. CHERNETS, A. O. KORNIENKO, S. V. FEDORCHUK, O. V. RADIONENKO

\section{CALCULATION ESTIMATION OF SERVICE LIFE OF CYLINDRICAL AND PLANE METAL POLYMER SLIDING GUIDES WITH BOUNDARY FRICTION}

Methods for calculating the contact pressures and service life of cylindrical and plane metalpolymer sliding guides are presented, which are based on the known methodology for studying the kinetics of wear of materials during sliding friction. The resource of both types of guides with hybrid conjugation of materials at different loads and radial gaps (cylindrical guide) is calculated. The guide slider is made of antifriction polymer composite material "Moglace", and its base is made of steel. The maximum initial contact pressures in the cylindrical guide are also determined. Quantitative and qualitative regularities of dependence of friction path and contact pressures on load and radial gap are established.

Keywords: cylindrical and plane metal-polymer guides, method of calculation of durability and loading capacity, service life of guides - path of friction, maximum contact pressures

\section{Referenses}

1. Andrejkiv A.E., Chernec M.V. Ocenka kontaktnogo vzaimodejstvija trushhihsja detalej mashin. - K.: Naukova dumka, 1991. $-160 \mathrm{~s}$.

2. Gorjacheva I.G., Dobychin N.M. Kontaktnye zadachi v tribologii. - M.: Mashinostroenie, 1988. - $256 \mathrm{~s}$.

3. Kovalenko E.V. K raschetu iznashivanija soprjazhenija val - vtulka // MMT. - 1982. № 6. - S.66-72.

4. Kravchuk A.S., Chigarev A.V. Mehanika kontaktnogo vzaimodejstvija tel s krugovymi granicami. - Minsk: Tehnoprint, 2000. - 198 s.

5. Kragel'skij I.V., Dobychin N.M., Kombalov V.S. Osnovy raschetov na trenie i iznos. M.: Mashinostroenie, 1977. -526 s.

6. Kuz'menko A.G. Razvitie metodov kontaktnoj tribomehaniki. - Hmel'nickij: HNU, 2010.

7. Teplyj M.I. Opredelenie kontaktnyh parametrov i iznosa v cilindricheskih oporah skol'zhenija // Trenie i iznos. - 1987. -№ 6. - S. 895-902.

8. Chernec M.V. K voprosu ob ocenke dolgovechnosti cilindricheskih tribosistem skol'zhenija s granicami, blizkimi k krugovym // Trenie i iznos. - 1996. -№ 3. - S. 340-344.

9. Czerniec M. Wytrzymałość stykowo - tarciowa oraz trwałość tribotechnicznych systemów ślizgowych. - Lublin: Wyd. Politechniki Lubelskiej, 2000. - 490 s.

10. Chernets M.V., Lebedeva N.M. K voprosu o vlyianyy maloi nekruhlosty эlementov tsylyndrycheskoi napravliaiushchei na ee dolhovechnost // Problemy trybolohii. - 2005. - №3. - S. $100-106$.

11. Chernets M.V., Liebiedieva N.M. Doslidzhennia vplyvu maloi nekruhlosti na resurs tsylindrychnoi napriamnoi // Problemy trybolohii. - 2006. -№4. - S. 52 - 55.

12. Chernets M.V., Andreikiv O.Ie., Liebiedieva N.M. Uzahalnenyi metod doslidzhennia trybokontaktnoi vzaiemodii $\mathrm{u}$ tsylindrychnyi napriamnii $\mathrm{z}$ riznotypnym ohranenniam yii elementiv // Mashynoznavstvo. - 2006. - №7. - S. 54 - 58.

13. Chernets M.V. Trybokontaktni zadachi dlia tsylindrychnykh ziednan $\mathrm{z}$ tekhnolohichnoiu nekruhlistiu. - Liublin: Vyd. Liublinskoi politekhniky, 2013. - 274 s.

14. Velboi V.P., Dykha M.O. Do rozrakhunku kontaktnykh parametriv i syl tertia v tsylindrychnykh napriamnykh kovzannia // Problemy trybolohii. -2016. - № 4. - S. $82-88$.

15. Chernets M. V., Ishchenko A. O., Korniienko A. O., Radionenko O. V., Fedorchuk S. V. Do pytannia pro metod rozrakhunku dovhovichnosti ploskykh napriamnykh kovzannia z elementamy z polimernykh kompozytiv // Problemy tertia ta znoshuvannia, 2020. - № 3 (88). - S.40-46. DOI: 10.18372/0370-2197.3(88).14919

16. Ishhenko A.A., Radionenko A.V., Ishhenko E.A. Issledovanie i primenenie polimernogo materiala «moglajs» dlja vosstanovlenija napravljajushhih poverhnostej salazok supportov metallorezhushhih stankov // Problemi tertja ta znoshuvannja. - 2014. - Vip.№1 (62). - S. 23 - 29. 